\title{
Research on the Experimental Teaching System of Economics and Management Based on SAP
}

\author{
Zhang Ruifeng $^{1, a}$, Zhang Yongjie ${ }^{2, b}$ Dong zhixiang ${ }^{3, c}$ \\ ${ }^{1}$ School of finance, Hebei University of Economics and Business, Shijiazhuang, 050061, China. \\ ${ }^{2}$ Dean's Office, Hebei University of Economics and Business, Shijiazhuang, 050061, China. \\ ${ }^{3}$ Institute of Hydrogeology and Environmental Geology, Chinese Academy of Geological Sciences, \\ Shijiazhuang, 050061, China. \\ azrf33310@163.com, b792676432@qqcom, 'email410692235@qq.com
}

Keywords: Experimental Teaching System, Economics and Management, SAP

\begin{abstract}
Experimental teaching course is an indispensable part in the process of cultivating management professionals and an important link in the cultivation of students' abilities and skills. On the one hand, it requires that colleges and universities pay attention to the understanding and mastery of professional knowledge in the process of personnel training. On the other hand, it requires to pay attention to the cultivation of students' practical ability and the improvement of comprehensive quality, professional skills, comprehensive quality and employment ability. Based on the analysis of the experimental teaching system of the national experimental centers of economics and management in China, we analyze the problems existing in the experimental teaching system of economics and management in Hebei University of Economics and Trade, and put forward the 360 experiment teaching system of Integrated and progressive enterprise operation simulation based on SAP technology in order to perfect the experimental teaching system of economics and management and improve the teaching quality.
\end{abstract}

\section{Introduction}

In the 21st century, the experimental teaching of economics and management has developed rapidly. In 2005, the Ministry of Education proposed to establish a number of State-level experimental teaching demonstration centers on the basis of the construction of experimental teaching centers in Colleges and universities. The construction goal is: "To establish an educational concept based on student-oriented, knowledge transfer, ability training, and quality improvement, and an experimental teaching concept centered on capacity development, establish an experimental teaching system that is conducive to cultivating students' practical and innovative abilities, build a high-quality experimental teaching team that meets the needs of modern experimental teaching and an experimental teaching environment with advanced equipment, resource sharing, and open services, and establish a modern and efficient operational management mechanism to comprehensively improve the level of experimental teaching. At present, there are 49 universities that have established experimental teaching center as a national experimental teaching demonstration center. Because of the different educational levels and training objectives, the experimental teaching system has its own characteristics. 


\section{Research Status}

\subsection{Experimental Teaching System of Economics and Management Combining Theory and Experiment}

Such colleges and universities include Peking University, Xiamen University, Nankai University, Xi'an Jiaotong University, Wuhan University, Shandong University, Renmin University of China, Chongqing University and so on. The experimental teaching of these colleges and universities is in the corresponding economics and management colleges. Due to the high level of school running, theoretical teaching and scientific research is domestic and even international, the experimental teaching concept is also highly positioned. For example, Renmin University of China takes the mission of "using modern information technology and statistical quantitative analysis methods to promote and support economic management discipline construction and scientific research" and takes the teaching philosophy of cultivating a "composite, innovative, research-oriented, pragmatic" social pillar. The teaching philosophy of Xiamen University is "to rely on the advantages of economic and management national key discipline groups, strengthen the cultivation of students' practical ability, innovation consciousness and innovation ability, form a three-level experimental teaching system of course business experiment, post group comprehensive experiment and open innovation experiment and the distinctive features of economic and management experiment teaching through the organic combination of experimental teaching and theoretical teaching and scientific research, and cultivate economic and management research qualified talents. In a word, the experiment teaching of management in 985 colleges and universities is closely combined with the construction and development of the specialty and cultivate students' comprehensive ability of innovation, research and pragmatism. The high theoretical level, scientific research ability and strong financial support of these colleges and universities have laid a solid foundation for the smooth implementation of the experiment teaching.

\subsection{Experimental Teaching System of Economics and Management for Innovative Ability}

Such colleges and universities include Shanghai University of Finance and Economics, Anhui University, Zhongnan University of Economics and Law, Guangxi University, Shihezi University and so on. There is a certain gap with 985 universities in terms of school-running level, theoretical teaching level, scientific research level and financial support, but the gap is small. The experiment teaching of economics and management of Anhui University, Zhongnan University of Economics and Law, Guangxi University and Shihezi University is also in the corresponding unified planning of the College of Economics and Management. The idea of experimental teaching in such colleges is worse than that in 985 colleges and universities. They focus on the cultivation of innovative ability. In fact, innovative ability to a certain extent means a strong research ability, otherwise the level of innovation will not be strong. The strength of 211 colleges and universities provide a strong backing for the cultivation of this ability.

\subsection{Experimental Teaching System of Economics and Management for Comprehensive Ability}

Such colleges and universities include Northeast University of Finance and Economics, Jiangxi University of Finance and Economics, Southwest University of Finance and Economics, Beijing University of Commerce and Industry, Guangdong University of Business, Hebei University of Economics and Trade, etc. The experimental teaching of management in these colleges and universities can be divided into two categories. One is the old-fashioned subordinate colleges and universities, such as Northeast University of Finance and Economics, Jiangxi University of Finance and Economics, Southwest University of Finance and Economics. These colleges and universities have higher levels of scientific research and teachers, which are on a par with 211 colleges and universities, even higher than them. Therefore, the concept and system of experimental education is also better. For example, the purpose of experimental teaching of Northeast University of Finance and Economics is to "verify theory, cultivate ability, and achieve integrity". They divide the experimental teaching into verifying experiment and researching experiment, so the project-based 
experiment becomes the characteristics of Northeast University of Finance and Economics. The other category is the local finance and economics colleges. Compared with the above institutions, there is a certain gap in the level of teachers, scientific research and their training objective is mainly to cultivate applied talents. For example, Guangdong University of Finance and Economics.

\section{Defects of the Economics and Management Experimental Teaching System of Hebei University of Economics and Business}

Hebei University of Economics and Business has always adhered to the concept of experimental teaching that takes the school training objectives as guidance, constantly updates the concept of education and teaching, takes the experimental teaching system as the core, the informatization as support, the simulation and modular experimental environment as the benchmark, and the standardized experimental teaching management as protection, cultivates high-quality applied talents with strong practical ability to meet the needs of social development.The four-year continuous experimental practice teaching system is based on the discipline construction, professional development as the goal, combined with theoretical teaching, with practical ability training as the core, forming five-level experimental projects of single-type experiment covering the curriculum, comprehensive curriculum experiment, professional comprehensive experiment, cross-professional comprehensive experiment and innovative entrepreneurship practice, including four practice links of experiments, training, professional internships, graduation thesis (graduation design), involving four modules of public basic course experiments, subject basic course experiments, professional courses experiments, professional development class experiments .Compared with the experimental teaching system of similar institutions, there are still some shortcomings:

$>$ The Flaws in the Construction of the Experimental Teaching System;

> The Establishment of Experimental Teaching System Fails to Reflect the "Question-oriented"

Research Characteristics;

$>$ Insufficient Innovation;

$>$ Lack of Interdisciplinary Experimental Systems;

\section{SAP Technology}

SAP(System, Applications, and Products in Data Processing) Core Product R/3 is a standard ERP software for distributed client/server environments. Its key functional modules include: sales and distribution, material management, production planning, quality management, factory repair, human resources, industrial solutions, offices and Communication, project system, asset management, control, financial accounting. The modular structure of the software guarantees the special solution requirements for the individual processing of the data.

SAP HANA(High-Performance Analytic Appliance) is an in-memory computing platform that supports enterprise on-premise deployment and cloud deployment models, accelerates business processes, enables smarter business operations, and simplifies the IT environment. SAP HANA organizes tables through efficient columnar storage to let you bypass unneeded data. In addition to the common line storage architecture, columnar storage can also be used. It means that your program does not have to wait for the database to get the unneeded data, because all the data in the columnar table is stored in an adjacent manner.

\section{Construction of the Experiment Teaching System under SAP Technology}

Guided by the National Medium- and Long-Term Education Reform and Development Program (2010-2020) "Support students to participate in scientific research, strengthen practical teaching links, strengthen employment and entrepreneurship education and employment guidance services.”, the research team analyzes the economic and management professional construction of Hebei University of Economics and Business and combines the characteristics of SAP technology to build a management experiment system based on the characteristics of Hebei iron and steel enterprises. 


\section{$5.1360^{\circ}$ Experiment Teaching System of Integrated and Progressive Enterprise Operation Simulation}

" $360^{\circ}$ experiment teaching system of Integrated and progressive enterprise operation simulation" (hereinafter referred to as " $360^{\circ}$ experiment teaching system ") focuses on the cultivation of students' multi-faceted abilities and progresses in layers according to three abilities (basic, professional, and comprehensive). The setting of the dimension is mainly based on the requirements of the society for the training of economic management talents, combined with the current situation of the discipline setting of Hebei University of Economics and Business, and moderately considering the trend of demand for future talents. According to the requirements of talent cultivation, a number of concentric circles are set up, which are carried out from the inside to the outside, reflecting the level of talent cultivation, as shown in Figure 1. At present, the dimension is set at 5 levels. The 1st layer of the center represents the training content of the basic ability. The third layer means that the basic qualified training goal is achieved. The students strive to reach the 5th level in their professional aspect and 3rd level in their relevant professional aspects when they graduate.

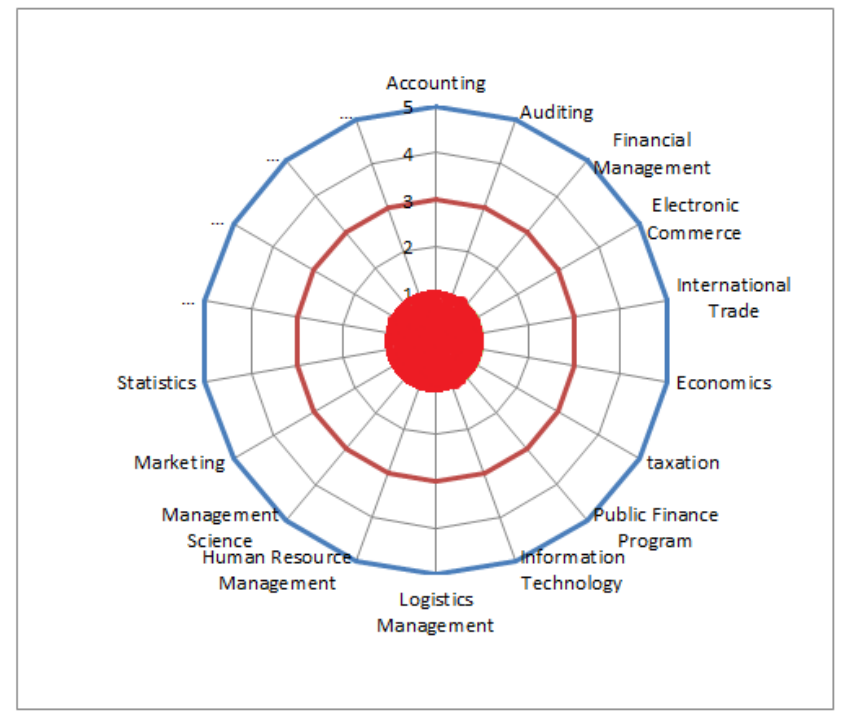

Figure $1360^{\circ}$ Experiment Teaching System

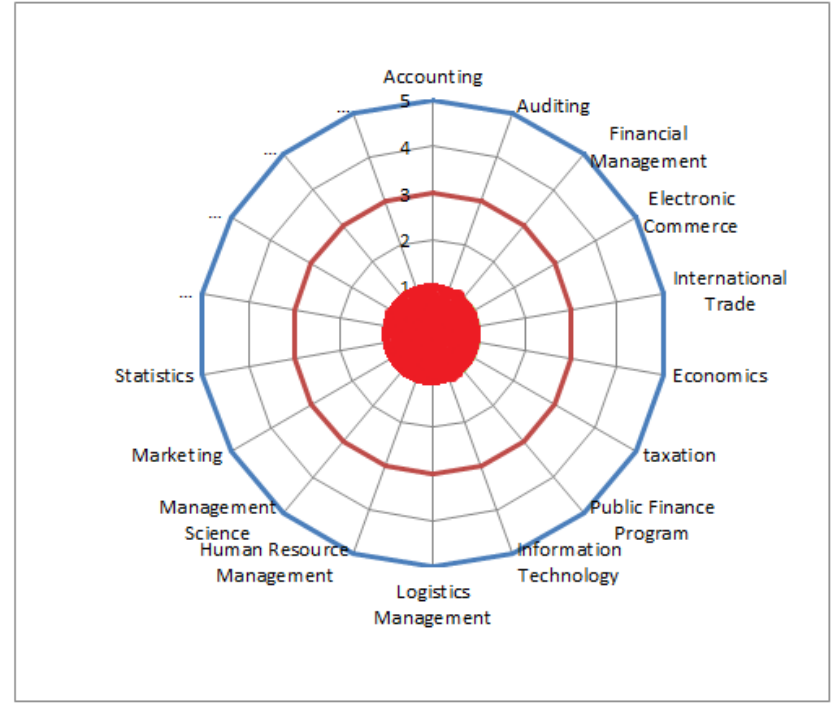

Figure 2 Basic Ability Training System

Students are in the 0th level when they enter the college. With the progress of the course and related experiments, the basic ability is constantly consolidated. At this stage, the principle of "thicken foundation" is adopted, and "general education" is emphasized. The relevant experiments are mainly based on "validation type". Through the verification of relevant theories, the understanding of the subject theory is deepened, which lays a solid foundation for further professional study. As shown in Figure 2. As the course progresses, the relevant experiments are progressive and professional skills are strengthened.

The cultivation of professional competence is mainly through individual experiments and comprehensive experiments in the professional courses and related courses. Through these experiments, students gradually deepen their understanding of the profession, master professional theory, and improve professional skills. However, relatively speaking, the skills of all aspects are relatively isolated and cannot be integrated. The phenomenon of "segmentation" is more serious. With the integration of different courses and the implementation of cross-professional comprehensive experiments, comprehensive and composite capabilities continue to strengthen. Take the accounting profession as an example. The ability of a student to graduate in various aspects is shown in Figure 3.

"360 experiment teaching system " provides "interdisciplinary comprehensive experiment", focusing on the cultivation of students' comprehensive ability, breaking the barriers of disciplines, perfecting general education, paying attention to the integration, intersection and penetration of knowledge, and strengthening compound cultivation. Through "360 experiment teaching system ", students will be trained in all aspects and at multiple levels, and strive to achieve the goal of "thicken 
foundation, widen caliber" and "general education + professional training”. At each level, relevant subdivision experiments or experimental projects are set up in different dimensions (discipline knowledge and skills) based on student characteristics and professional requirements. Through subdivided experiments or experimental projects, students' practical ability will be strengthened and the overall quality of students will be enhanced. According to the "360 integrated and progressive" training concept, the research team rely on various relevant colleges to reorganize the professional curriculum system, especially the courses and experiments related to practical ability training. Take the accounting profession as an example, as shown in Figure 4.

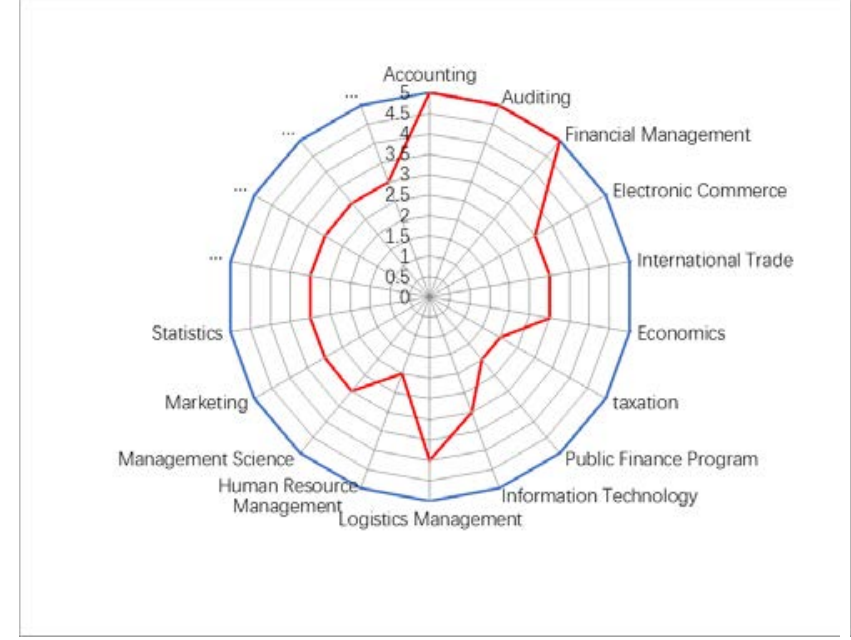

Figure 3 Inter-Professional Capacity Development

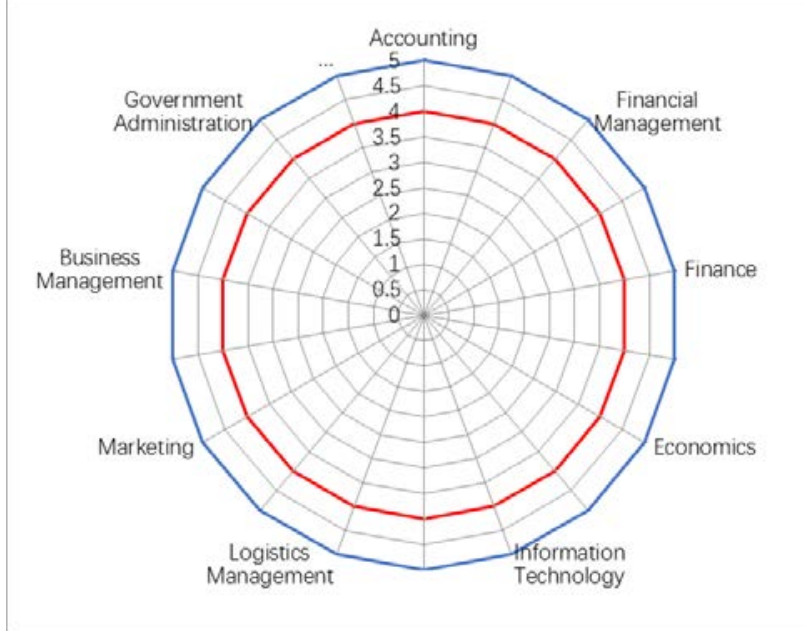

Figure 4 Experiment Course System Design

The relevant experimental projects also design relevant dimensions based on the " $360^{\circ}$ all-round, progressive " training concept and the experimental purpose and requirements. Taking accounts receivable processing as an example, as shown in Figure 5. According to the principle of "strengthen ability", combined with the training goal of "General Education + Professional Training", "360 experiment teaching system " provides unified planning of students' skills, as shown in Figure 6.

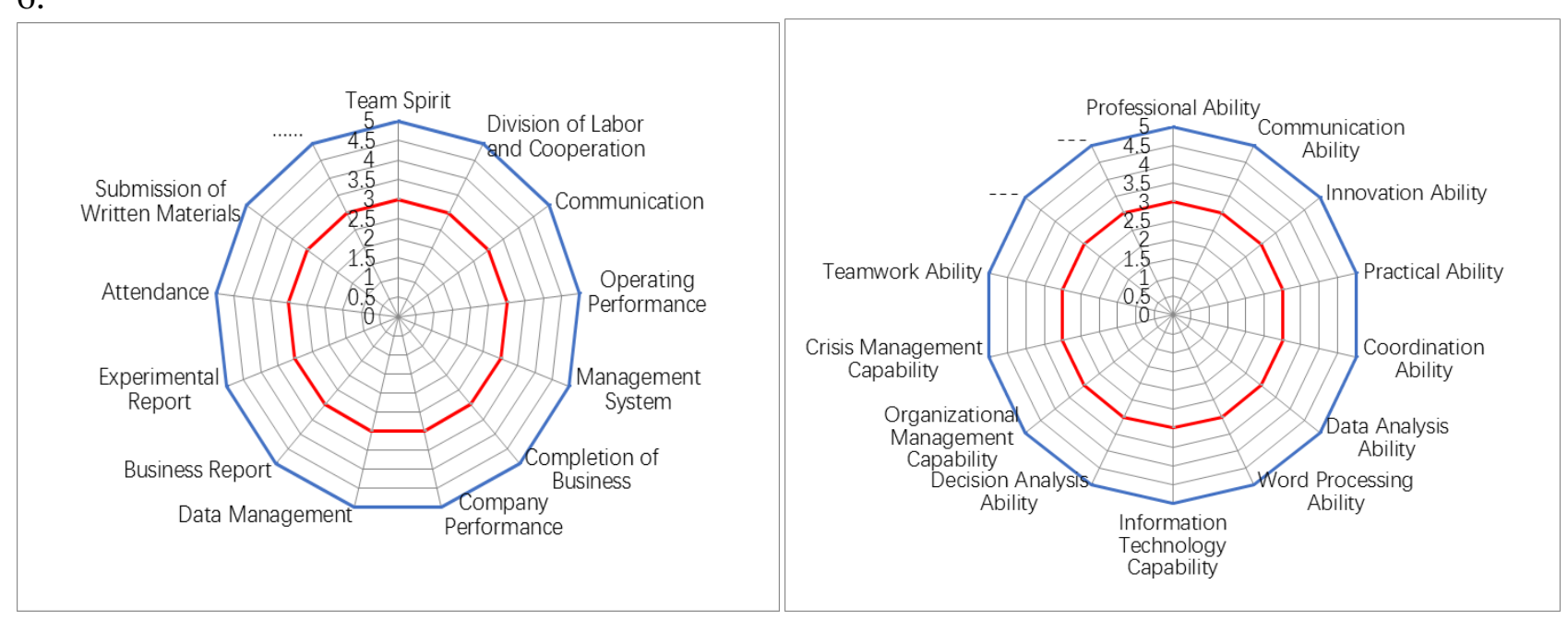

Figure 5 Experiment Project Design

Figure 6 Student Skills Development System

In short, the "360。 experiment teaching system" has always been based on the principle of "thicken foundation, widen caliber, focus practice, strengthen ability", conscientiously implemented the training goal of "General Education + Professional Training". On the basis of promoting general education, it cultivates students step by step in different dimensions to highlight its professional characteristics, strengthen compound cultivation, and improve the overall quality and abilities of the students. 


\subsection{Management Platform for the Integration of Iron and Steel Enterprise}

Along with the comprehensive deepening of teaching reform, in order to effectively operate the "360。 experiment teaching system ", the research team set up a virtual simulation experiment platform for the profession (or course) involved in "market research, product development, design, manufacturing, sales, recycling and other stages" - "the management platform for the integration of steel enterprises." which takes the product life cycle as the main line. The platform is based on a large number of investigations and sufficient argumentation. It is also according to typical meaning of the iron and steel enterprises in Hebei economic and social development. It combines the characteristics of "complexity, randomness, irreversibility" in enterprise operation management and the characteristics of modern manufacturing industry with "big manufacturing, whole process, multidisciplinary intersection”. The platform uses advanced SAP technology and modern management concepts to unify all kinds of experimental teaching software in colleges and universities, breaks through various experimental teaching software, realizes data, curriculum system and teaching resources sharing. It not only runs through all the professional curriculum systems and teaching resources of the university, but also integrates all relevant teaching software with the process. As shown in Figure 7.

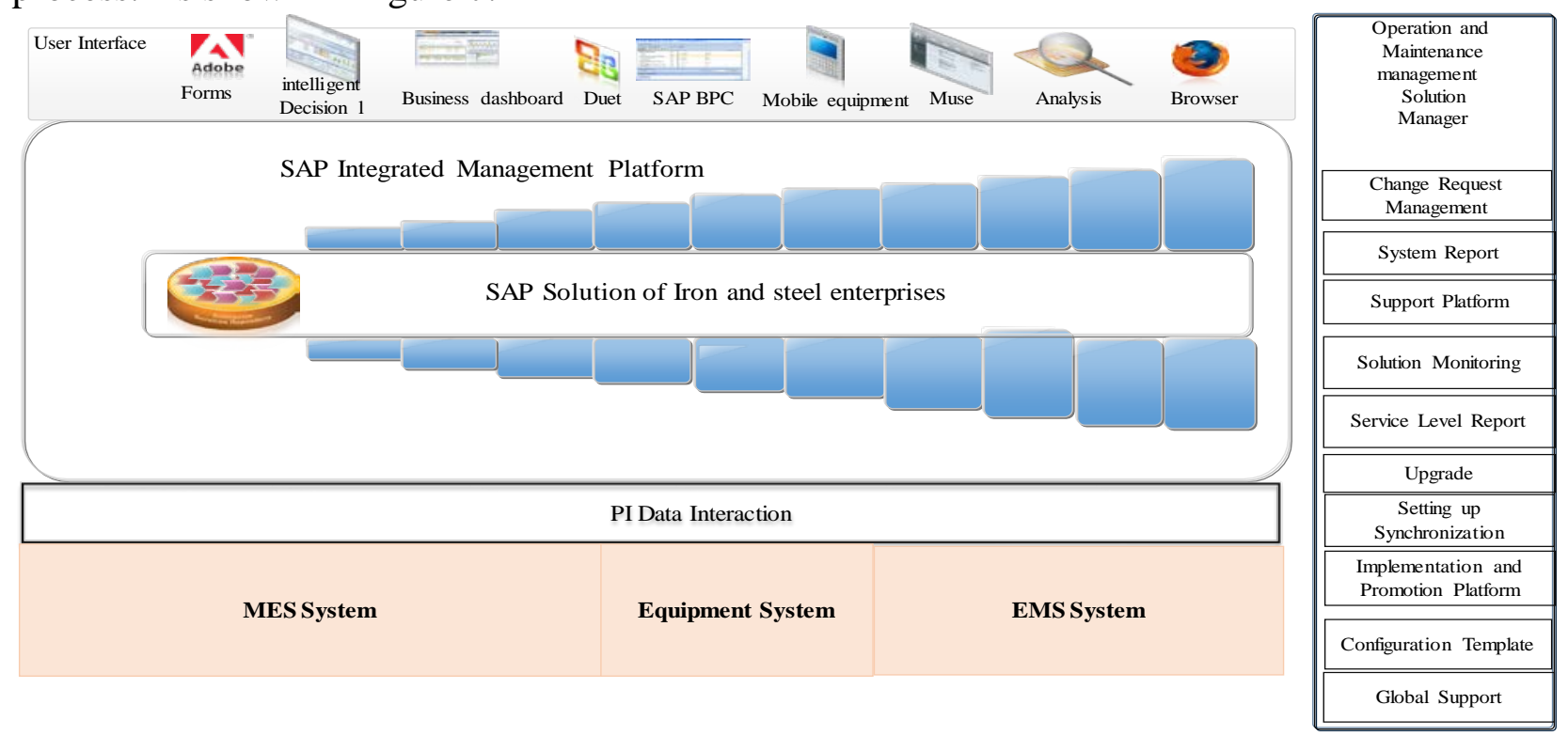

Figure 7: SAP Integrated Management Platform

\section{Acknowledgments}

Major projects in teaching research of Hebei University of Economics and Business(NO: 2013JYZ05, Research on the construction of economic management practice curriculum system).

\section{Reference}

[ 1 ] Joint Committee of State-level Experimental Teaching Demonstration Center Disciplines of Economy and Management, Reform, Innovate, Demonstration, Guide: Construction achievement report of State-level Experimental Teaching Demonstration Center(Economy and Management) [M]. Beijing: Economic Science Press, 2017,8.

[ 2 ] SAP R/3 System working principle, https://blog.csdn.net/minwang593/article/details/17549987.

[ 3 ] SAP HANA Overview, https://www.sap.com/china/products/hana.html.

[ 4 ] The PISA 2003 Assessment Framework: Mathematics, Reading, Science and Problem Solving Knowledge and Skills, https://files.eric.ed.gov/fulltext/ED480801.pdf.

[ 5 ] Liu hong-qian, Study on Sustainable Development Countermeasures of National Demonstration Center for Experimental Economic and Management Education-A Case Study of Jiangxi University of Finance and Economics [D]. Jiangxi University of Finance and Economics, 2017.

[ 6 ] Qi Gui-jie, Shen Fu-ping, Zhang Rui-feng, Exploration and practice of innovation and Entrepreneurship Education[M]. Beijing: Economic Science Press, 2018,7. 